\title{
A Model Study of Gravity Waves over Hurricane Humberto (2001)
}

\author{
M. A. KUESTER \\ National Ecological Observatory Network, Inc., Boulder, Colorado \\ M. J. AleXAnder \\ Colorado Research Associates Division, NWRA, Boulder, Colorado
}

E. A. RAY

Chemical Sciences Division, NOAA/Earth Systems Research Laboratory, and CIRES, University of Colorado, Boulder, Colorado

(Manuscript received 12 December 2006, in final form 11 February 2008)

\begin{abstract}
Atmospheric gravity waves are known to influence global circulations. Understanding these waves and their sources help to develop parameterizations that include their effects in climate and weather forecasting models. Deep convection is believed to be a major source for these waves and hurricanes may be particularly intense sources. Simulations of Hurricane Humberto (2001) are studied using the fifth-generation Pennsylvania State University-National Center for Atmospheric Research (PSU-NCAR) Mesoscale Model (MM5). Humberto is simulated at both tropical storm and hurricane stages. Fourier transform and wavelet analysis are employed to investigate wave characteristics and their behavior in the lower stratosphere. The Fourier analysis gives a regional view of storm affects, whereas wavelet analysis gives a local picture of isolated events. Analysis of the movement of convective sources and local winds gives further insight into the mechanisms that can cause gravity waves. Convectively generated gravity waves are observed in the lower stratosphere of this model with horizontal scales of $15-300 \mathrm{~km}$, vertical scales of $4-8 \mathrm{~km}$, and intrinsic periods of approximately $20-100 \mathrm{~min}$.
\end{abstract}

\section{Introduction}

Deep convection generates upward-propagating gravity waves, which are important to forcing the largescale atmospheric circulation (Piani et al. 2000), and hurricane-induced gravity waves are one contributor to this forcing. Convectively generated gravity waves have been observed in the stratosphere with horizontal scales of tens to hundreds of kilometers, vertical scales of up to about $10 \mathrm{~km}$, and intrinsic periods of $10 \mathrm{~min}$ and larger (Alexander and Pfister 1995; Dewan et al. 1998; Pfister et al. 1986; Pfister et al.1993; Wang et al. 2006). It has been shown that gravity waves at these smaller scales play a key role in the vertical transport of

Corresponding author address: M. A. Kuester, National Ecological Observatory Network (NEON), Inc., 3223 Arapahoe Ave., Suite 210, Boulder, CO 80303.

E-mail: mkuester@neoninc.org momentum within the atmosphere and can have a significant influence on the mean circulation and dynamics of the middle atmosphere (Fritts and Alexander 2003). Because these smaller scales are not resolved in current general circulation models (GCMs) because of their coarse spatial resolution, the important dynamical effects caused by these gravity waves must be parameterized (Beres et al. 2004; Chun and Baik 1998). The parameterization of this forcing is a difficult problem because the spatial and temporal variability of forcing within convection is still poorly known and wave generation is not clearly understood (Song and Chun 2005). Ongoing research investigates the sources and mechanisms that generate gravity waves and the momentum flux (MF) they carry to the middle atmosphere. For example, Kim et al. (2005) simulated 300$600-\mathrm{km}$ waves above a hurricane in a model with $27-\mathrm{km}$ horizontal resolution. The study presented here uses a near-cloud-resolving model with a 3-km horizontal spa- 
tial resolution and explicit microphysics so that smallerscale waves and their generation mechanisms may be resolved and investigated.

There are three outstanding mechanism theories for wave generation. One is the "deep heating" mechanism, which suggests that the wave forcing is the timedependent, spatially localized latent heat release in convective storms (Holton et al. 2002). Another mechanism is the mechanical "oscillator" mechanism, which suggests that a parcel of air rises to its level of neutral buoyancy and oscillates at the local buoyancy frequency, displacing the isentropes of a stable layer directly above (Fovell et al. 1992; Lane et al. 2001). The third mechanism, the "obstacle effect," suggests that the turrets of a convective storm can act as a barrier to background flow, creating an obstacle and generating waves via a mechanism that resembles mountain wave formation (Pfister et al. 1993). In reality, these are idealized simplifications of how gravity waves are generated, and in most cases combinations of these or other yet unknown mechanisms are coupled through nonlinear forcing terms. Recent attempts to model gravity wave generation have suggested that there is a complex relationship between these forcings and background environmental conditions (Beres et al. 2002; Song et al. 2003). It has also been shown that a wind-filtering mechanism can further affect waves as they propagate away from the source. Winds along the path of wave propagation act to reduce the momentum flux of waves propagating in the same direction as these mean winds (Beres et al. 2002). Evidence for these mechanisms is investigated for the tropical cyclone environment.

Manzini and McFarlane (1998) reported zonal monthly averaged eastward tropopause momentum fluxes from the gravity wave parameterization in a GCM study at $1-2.5 \times 10^{-3} \mathrm{~N} \mathrm{~m}^{-2}$ in the summer subtropics. To model the quasi-biennial oscillation (QBO), global models require zonal averaged yearly fluxes in the tropics on the order of $3-6 \times 10^{-3} \mathrm{~Pa}$ (Dunkerton 1997; Giorgetta et al. 2002; Scaife et al. 2000). Alexander et al. (2000) found local event momentum fluxes of $0.11 \mathrm{~N} \mathrm{~m}^{-2}$ associated with 10-100$\mathrm{km}$-wavelength waves over deep convective cloud tops during the Stratosphere-Troposphere Exchange Project (STEP) campaign in the tropics. Maximum measurements of local event momentum flux at $20 \mathrm{~km}$ during Typhoon Kelly (1987) were found to be 0.4 $\mathrm{m}^{2} \mathrm{~s}^{-2}\left(\sim 0.04 \mathrm{~N} \mathrm{~m}^{-2}\right)$ by Sato (1993). We also determine momentum flux in wave events for comparison to previous research on subtropical forcing to show the role of hurricane-induced wave generation in this forcing. One must be careful when comparing these results because they are determined via several different aver- aging methods over different resolutions and sampling rates.

In this paper, regional and local analysis tools are used to investigate wave sources, properties, and behavior in the lower stratosphere above a tropical cyclone environment. Simulations of Humberto are developed using the fifth-generation Pennsylvania State University -National Center for Atmospheric Research (PSU-NCAR) Mesoscale Model (MM5). Humberto was observed in September 2001 during the fourth field campaign in the National Aeronautics and Space Administration's (NASA's) Convection and Moisture Experiment series (CAMEX-4) (Kakar et al. 2006). Humberto became a category 2 storm at its maximum intensity on 24 September 2001 (Beven et al. 2003). Humberto is simulated for tropical storm and hurricane stages on 22 September 2001 and 24 September 2001, respectively.

The outline of the remainder of this paper is as follows: A brief description of the numerical model and comparisons to observations of Humberto are presented in section 2. Our analysis approach is presented in section 3. In section 4, Fourier analysis is applied to the model to examine overall regional wave behavior. In section 5, local events are chosen for study and wave analysis methodologies, including wavelet analysis, are used to investigate these isolated events. Investigations of wave sources and wave generation are presented in section 6. Characteristics of waves and their possible sources are presented, along with local and regional calculations of momentum fluxes. Section 7 is a discussion of key findings including evidence for specific source mechanisms. Finally, in section 8, our results and conclusions are summarized.

\section{Description of the numerical model and model validation}

Stratospheric gravity waves within a developing tropical cyclone environment are investigated using a high-resolution near-cloud-resolving numerical simulation with MM5 (Dudhia 1993; Grell et al. 1995). For this simulation, the model configuration consists of triply nested one-way grids with domains of horizontal grid spacing at $27 \mathrm{~km}$ (coarse domain), $9 \mathrm{~km}$ (nest 1) and 3 $\mathrm{km}$ (nest 2). The one-way nest allows adjustments of parameterizations or domain locations of the inner domain to be run separately from the outer domains with much shorter computation time than a two-way nest. Nest 2 results are used for wave analysis. Table 1 summarizes the model domain configurations. There are 50 vertical levels between the surface and the $10-\mathrm{hPa}$ pressure level, which corresponds to an altitude of approxi- 
TABLE 1. Time and domain configurations for the two model runs of Humberto.

\begin{tabular}{lccc}
\hline \hline \multicolumn{1}{c}{ Domain } & Domain 1 (coarse) & Domain 2 (nest 1) & Domain 3 (nest 2) \\
\hline Grid size (km) & 27 & 9 & 3 \\
Number of grid points: & $121 \times 137$ & $133 \times 148$ & $157 \times 166$ \\
22 Sep 2001 simulation & $121 \times 137$ & $142 \times 151$ & $160 \times 169$ \\
24 Sep 2001 simulation & 35 & 35 & 50 \\
$\sigma$ levels & 30 & 20 & 3 \\
Time steps (s) & & & \\
Run time (time in UTC): & 0000 UTC 22 Sep-0600 UTC & 0300 UTC 22 Sep-0000 UTC & 1400 UTC 22 Sep-2200 UTC \\
22 Sep 2001 simulation & 23 Sep 2001 & 23 Sep 2001 & 2001 \\
24 Sep 2001 simulation & 1200 UTC 23 Sep-0000 UTC & 2100 UTC 23 Sep-0000 UTC & 1600 UTC 24 Sep-0000 UTC \\
& 25 Sep 2001 & 25 Sep 2001 Sep 2001 \\
\hline
\end{tabular}

mately $30 \mathrm{~km}$. There are 14 layers in the region from $15-25 \mathrm{~km}$, which is the region of the lower stratosphere under study.

National Centers for Environmental Prediction (NCEP) Aviation Model data are used for initialization of the coarse domain and are also used for the bottom and lateral boundary conditions at 6-h intervals on the coarse domain. The coarse domain itself is used to initialize and define boundary conditions for the smaller nested domains. A bogus vortex is used during the initialization of the coarse domain. National Hurricane Center best-track maximum wind speed and sea level pressure data are used to create a symmetric vortex that is put into the initial meteorological boundary conditions (Davis and Low-Nam 2001). An upper radiation condition is applied to reduce the reflection of energy and to prevent spurious noise buildup near the top boundary. Gravity waves found in this study are approximately $15-300 \mathrm{~km}$ in horizontal wavelength. Because of the $3-\mathrm{km}$ resolution of the smallest nest, wave- length components smaller than about $15 \mathrm{~km}$ are damped by the numerical dissipation.

The model is run separately for each day considered in this study and is run on time intervals of $30 \mathrm{~s}$ for the coarse domain, $20 \mathrm{~s}$ for nest 1 , and $3 \mathrm{~s}$ for nest 2 over the length of the simulation. Two separate runs-versus one longer run-were used to minimize computing time. The model domains for the tropical storm and hurricane cases are shown in Fig. 1, along with storm center location comparisons between model and observations. Figure 2 compares model output minimum sea level pressure and maximum wind velocities to $\mathrm{Na}$ tional Hurricane Center reported observations. On 22 September 2001 the observed minimum pressure was $998 \mathrm{hPa}$ and the maximum winds observed were 26 $\mathrm{m} \mathrm{s}^{-1}$ at 2100 UTC. The storm track moved toward the northwest at approximately $5 \mathrm{~m} \mathrm{~s}^{-1}$. The tropical storm progressed to category 1 with a brief period of category 2 intensity on 24 September, with maximum winds of 44 $\mathrm{m} \mathrm{s}^{-1}$ and a minimum pressure of $983 \mathrm{hPa}$ at 0300 UTC.
MM5 Domains 20010922 Tropical Storm Case

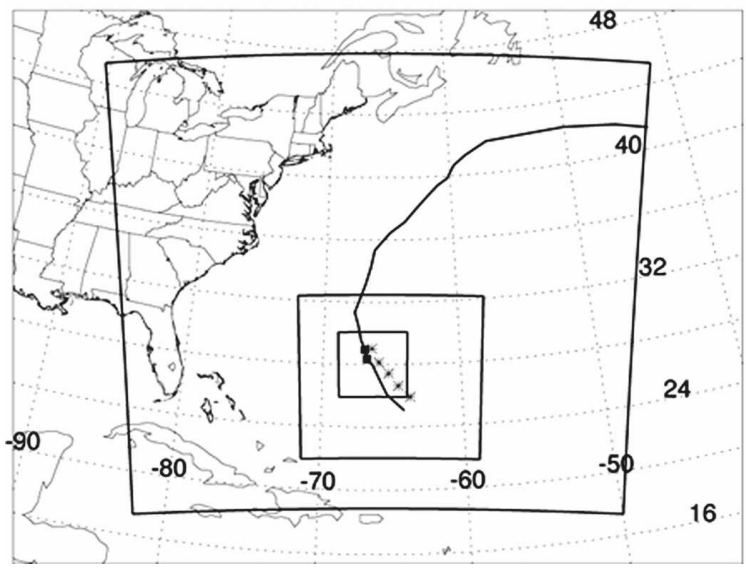

MM5 Domains 20010924 Hurricane Case

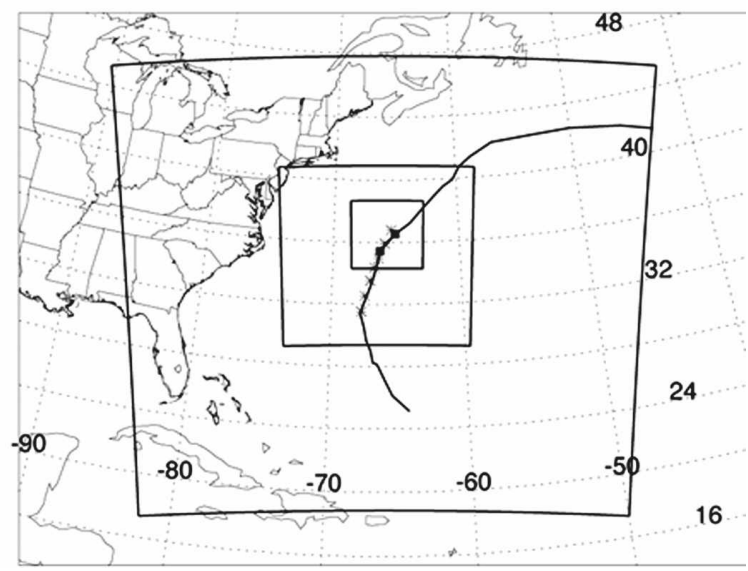

FIG. 1. Model domains for the tropical storm and hurricane cases. Storm center location observations are black boxes and modeled locations are asterisks. 

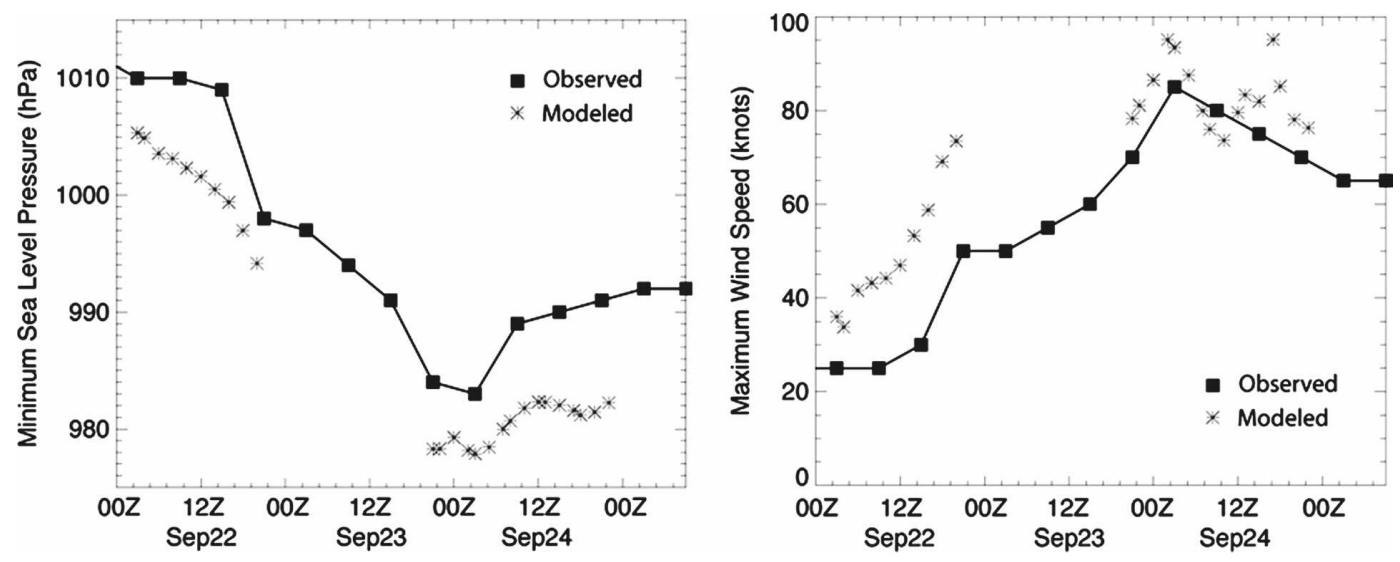

FIG. 2. National Hurricane Center observed minimum sea level pressure (hPa) and maximum wind speed (knots) for Humberto compared to modeled results.

The two days presented in this study were chosen because they coincide with NASA ER-2 Doppler radar (EDOP) measurements of Humberto during the CAMEX-4 mission (Heymsfield et al. 1996; Heymsfield et al. 2006). Differences between the tropical storm and hurricane deep convection are investigated using EDOP observations and model data in Fig. 3. Total integrated column reflectivity and total integrated column rainwater give an indication of the heating; cloud top height is a proxy for depth of heating. In the EDOP observations, nearly $95 \%$ of reflectivity returns correspond to a significant peak at $14-16-\mathrm{km}$ cloud top heights for the tropical storm. This same amount is more spread out over 9-14-km cloud top heights for the hurricane. In the model, the greatest amount of rainwater corresponds to $14-16-\mathrm{km}$ cloud top heights for the tropical storm and $12-14 \mathrm{~km}$ for the hurricane, with about $50 \%$ of the total rainwater falling from clouds at these heights for both cases. Deep intense convection, so-called "hot towers," are said to be more significant in the developing stages of an intensifying tropical cyclone (Kelley and Stout 2004), and this result is reflected here.

\section{Wave analysis methodology}

We analyze wind perturbations in the lower stratosphere to infer the properties of gravity waves in the model. Fourier analysis of the nest-2 domain is used to look at overall regional wave characteristics. Local analysis techniques are then used to investigate specific events. We use wavelet analysis to find the dominant horizontal and vertical wavelengths in localized events with relatively large momentum fluxes. Investigation into the locations and motion of deep convective re-
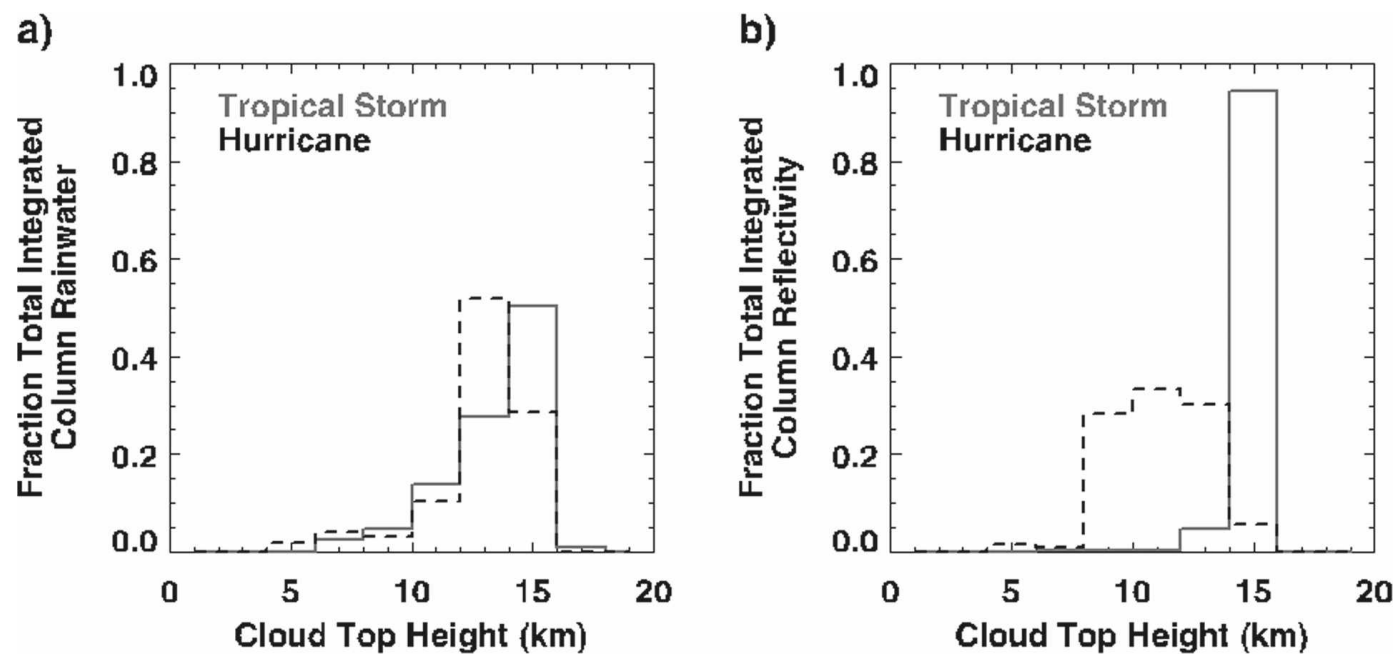

FIG. 3. Histograms showing (a) the fraction total integrated column rainwater corresponding to cloud top heights in the modeled storms and (b) the fraction total integrated column reflectivity corresponding to cloud top heights in the storms observed by the EDOP. 
gions and background wind velocities at these sources are used to further study wave generation mechanisms.

Wave perturbations in the wind fields must first be calculated from the model output before wave analysis is performed. Velocity perturbations are calculated in two steps for the horizontal wind components. At each altitude, the velocity is averaged over the horizontal spatial domain and time (excluding the model ramp up). This mean velocity profile is subtracted from the total velocity field at each corresponding altitude. After the mean winds are subtracted, there are still largescale gradients in the data, reflective of the azimuthal mean structure of the storm, that must be removed. Although waves can exist at storm scales, the model domain is not large enough to clearly separate the mesoscale storm circulation from waves with similar scales. A sine regression is used to fit the storm-scale wind gradients and the resulting function is subtracted, leaving smaller-scale perturbations to study. The resulting data are velocity perturbations in the winds with larger storm structure removed. The removal of largescale variations is not necessary for the vertical velocity perturbations.

To look at stratospheric gravity waves created above Humberto in the model, we focus on altitudes near 20 $\mathrm{km}$, which is at least $5 \mathrm{~km}$ above the tropopause and 10 $\mathrm{km}$ below the model top. This approach keeps interpretation from being influenced by diabatic heating or any unphysical effects at the model top boundary. Wave characteristics, including horizontal and vertical wavenumber, intrinsic frequencies, phase speeds, group velocities, and propagation directions are found with the results of the spectral analysis and linear gravity wave theory.

\section{Analysis of regional characteristics}

A three-dimensional complex cospectrum is created by computing the Fourier transforms of the wind perturbation fields $u^{\prime}(x, y, t), v^{\prime}(x, y, t)$ and $w^{\prime}(x, y, t)$, giving the transformed variables $U\left(k_{x}, k_{y}, \omega\right), V\left(k_{x}, k_{y}\right.$, $\omega)$, and $W\left(k_{x}, k_{y}, \omega\right)$, where $\left(k_{x}, k_{y}\right)$ is horizontal wavenumber vector and $\omega$ is the wave frequency (Alexander et al. 2004). The cospectrums of $\left(u^{\prime}, w^{\prime}\right)$ and $\left(v^{\prime}, w^{\prime}\right)$ are then given by

$$
\begin{aligned}
& \operatorname{Co}_{u}=\operatorname{Re}\left\{U W^{*}\right\} \quad \text { and } \\
& \operatorname{Co}_{v}=\operatorname{Re}\left\{V W^{*}\right\},
\end{aligned}
$$

where $W^{*}$ is the complex conjugate of $W$. These cospectra are then rebinned to the cospectra of $(\phi, c)$ and $(\phi$, $\left.k_{H}, \omega\right)$, where $\phi$ is the wave propagation angle counterclockwise from east, $c$ is the phase speed, and $k_{H}$ is the horizontal wavenumber. These cospectra are normalized so that they are in spectral density units of $\mathrm{m}^{2}$ $\mathrm{s}^{-2} / \Delta \phi / \Delta c$ (where $\Delta \phi$ is $10^{\circ}$ and $\Delta c$ is $2 \mathrm{~m} \mathrm{~s}^{-1}$ ) and $\mathrm{m}^{2}$ $\mathrm{s}^{-2} / \Delta \phi / \Delta k_{H} / \Delta \omega$ (where $\Delta k_{H}$ is $0.0126 \mathrm{~km}^{-1}$ and $\Delta \omega$ is $\left.2.21 \times 10^{-5} \mathrm{~s}^{-1}\right)$.

An event momentum flux (EMF) spectrum over the investigated time period and model domain can be calculated at each point in $\phi-c$ space by

$$
\mathrm{EMF}=\frac{1}{2} \overline{\rho_{0}} \sqrt{\left[\mathrm{Co}_{u}(\phi, c) \Delta \phi \Delta c\right]^{2}+\left[\mathrm{Co}_{v}(\phi, c) \Delta \phi \Delta c\right]^{2}} .
$$

The same calculation can be done for the cospectra with respect to propagation direction and wavenumber.

An integrated momentum flux (IMF) can be calculated over the entire domain from Fourier analysis results in $\phi-c$ space by

$$
\mathrm{IMF}=\frac{1}{2} \overline{\rho_{0}} \sqrt{\left[\iint \operatorname{Co}_{u}(\phi, c) d \phi d c\right]^{2}+\left[\iint \operatorname{Co}_{v}(\phi, c) d \phi d c\right]^{2}}
$$

The IMF is calculated as the total momentum flux averaged over the entire domain in space and time and integrated over all intrinsic phase speeds and propagation directions. This calculation of momentum flux can be compared to regional values used in GCMs as well as with regional satellite measurements when scaled appropriately.

It would be wise to look at the sampling rates for this data to confirm that this Fourier analysis is an appropriate approach for use with the model. A rule of thumb states that the Nyquist frequency (sampling rate) should be at least twice as fast as the highest wave- form frequency. The Nyquist frequency for this dataset is $0.0175 \mathrm{~s}^{-1}$. For the 8-h dataset $\Delta \omega=2.21 \times 10^{-5} \mathrm{~s}^{-1}$. The expected frequencies for this type of data are on the order of $1-5 \times 10^{-3} \mathrm{~s}^{-1}$, so this sampling should give a sufficient picture of the wave activity. The wavenumber resolution in this method is set by the total distance across the domain, which is approximately 500 $\mathrm{km}$. As stated earlier, it is already expected that horizontal wavelengths less than $15 \mathrm{~km}$ will probably not be resolved with this model.

The Fourier analysis gives a picture of regional wave activity over the entire model domain in space and 


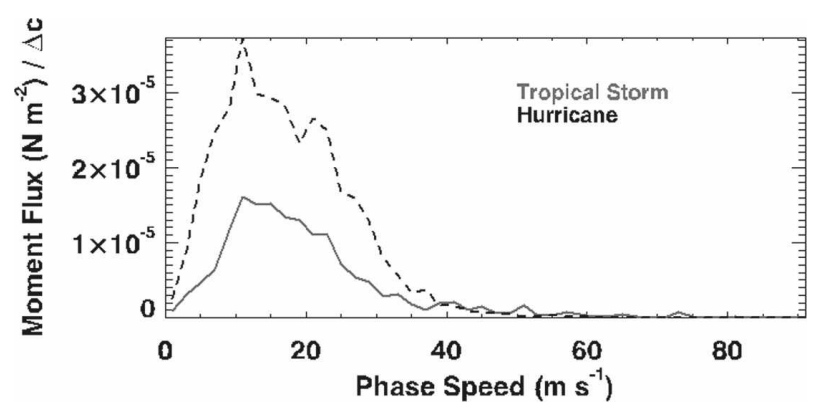

FIG. 4. Phase speeds associated with waves in model integrated over wavenumber.

time. Plots of $\operatorname{EMF}(c)$ integrated over wavenumber and $\operatorname{EMF}(k)$ integrated over phase speed are shown in Figs. 4 and 5, respectively. For both the tropical storm and hurricane cases, horizontal wavelengths are found within 15 to $300 \mathrm{~km}$ with a range of phase speeds from 5 to $40 \mathrm{~m} \mathrm{~s}^{-1}$ in the lower stratosphere. Waves at 15 $100 \mathrm{~km}$ wavelengths carry about twice the momentum flux as longer waves.

Figure 6 shows momentum flux versus frequency and wavenumber for the tropical storm and hurricane. For the tropical storm, the waves with the largest momentum flux have a horizontal wavelength of $85 \mathrm{~km}$, intrinsic frequency (period) of $0.0015 \mathrm{~s}^{-1}(69 \mathrm{~min})$, a groundrelative phase speed of $19.6 \mathrm{~m} \mathrm{~s}^{-1}$, and group velocity of the same speed. Propagation directions are spread across all azimuths, but there are momentum flux peaks for northeastward- and southeastward-propagating waves, with a maximum at $325^{\circ}$. For the hurricane, waves are found to be highly directional; mostly propagating southeastward, and the dominant mode is a horizontal wavelength of $86 \mathrm{~km}$, traveling $305^{\circ}$ with an intrinsic frequency (period) of $0.0011 \mathrm{~s}^{-1}(96 \mathrm{~min}$ ) at a ground-relative phase speed of $14.6 \mathrm{~m} \mathrm{~s}^{-1}$ and group velocity of $14.5 \mathrm{~m} \mathrm{~s}^{-1}$. The tropical storm (Fig. 6a) shows a greater spread to higher frequencies, whereas the hurricane wave frequencies (Fig. 6b) are more concentrated below $0.0015 \mathrm{~s}^{-1}$. The IMF for the tropical storm case is $8.2 \times 10^{-5} \mathrm{~N} \mathrm{~m}^{-2}$ and for the hurricane is $8.1 \times 10^{-4} \mathrm{~N} \mathrm{~m}^{-2}$. The dominant wave mode properties and integrated flux are summarized in Table 2 .

The Fourier analysis was also computed in four smaller domain quadrants northeast, northwest, southwest, and southeast of the center for both the tropical storm and hurricane cases and some results are shown in Table 3. The tropical storm case shows more regional variation, with ground-relative phase speeds ranging from 9 to $32 \mathrm{~m} \mathrm{~s}^{-1}$ and horizontal wavelengths ranging from 43 to $152 \mathrm{~km}$ across the quadrants. The hurricane case shows more similarity between quadrants, with ground-relative phase speeds ranging from 7 to $13 \mathrm{~m} \mathrm{~s}^{-1}$

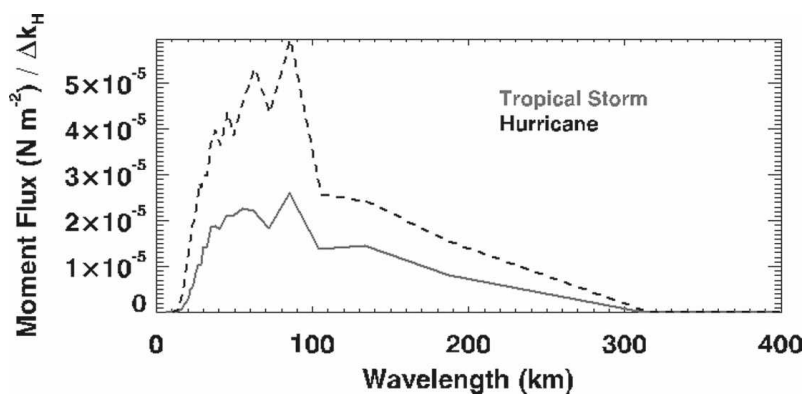

FIG. 5. Wavelength spectrum associated with waves in model integrated over phase speed.

and wavelengths ranging from 67 to $94 \mathrm{~km}$. For both cases, the greatest convective activity (inferred from total rainwater contained within each quadrant domain) appears to be on the leading (northern) side of the storm, with respect to the storm track. For the tropical storm case, the largest momentum fluxes appear on the leading right (northeast) side of the storm. This observation was also made by Sato (1993), who found enhanced gravity wave activity above storm rainbands on the leading side of a developing typhoon. For the hurricane case, however, the largest momentum fluxes are found on the trailing right (southeast) side of the storm, suggesting a possible difference in wave generation between developing and mature stage storms.

\section{Analysis of localized events}

Identifying individual wave sources within the storm will allow us to examine wave generation mechanisms and local wave properties. For the significant wave events in this model, apparent sources are found to be hot towers in the eyewall and rainbands of the storm, which are the most convectively active regions in the model. Because most convective heating occurs in updrafts, the mean vertical velocity from 5 - to $10-\mathrm{km}$ heights is used to identify the most convectively active regions, which should correspond to regions with intense heating. To choose a source to study, isolated regions that show both significant rainfall rates of at least $25 \mathrm{~mm} \mathrm{hr}^{-1}$ and an average updraft greater than 4 $\mathrm{m} \mathrm{s}^{-1}$ are chosen.

In the tropical storm case, an example is found to the south of the eye (as shown in Fig. 7a); this source is chosen because it is separated from other events and can be studied as a single, isolated event. There is a small region of significant updraft and rainfall rates at $27.83^{\circ} \mathrm{N}, 66.05^{\circ} \mathrm{W}$ beginning at $1648 \mathrm{UTC}$. The rainfall rate and average updraft speeds remain above the set threshold for about $10 \mathrm{~min}$. At 1654 UTC, wave struc- 
a)

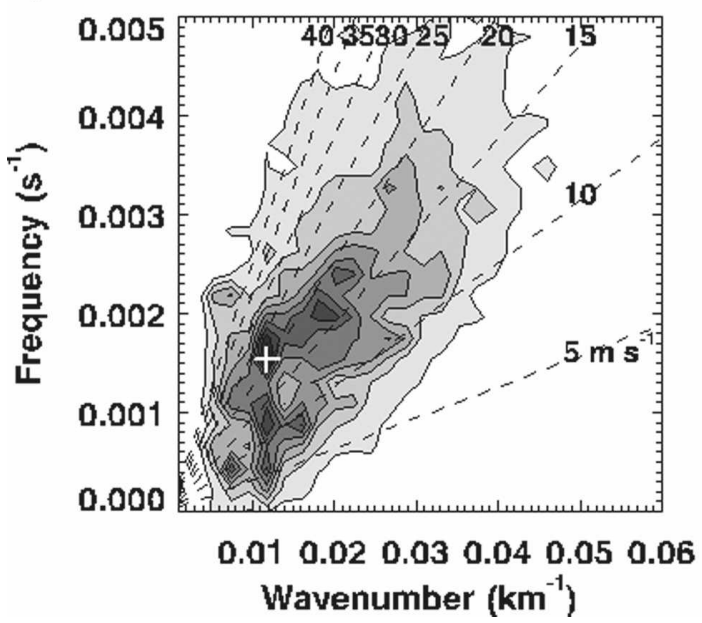

b)

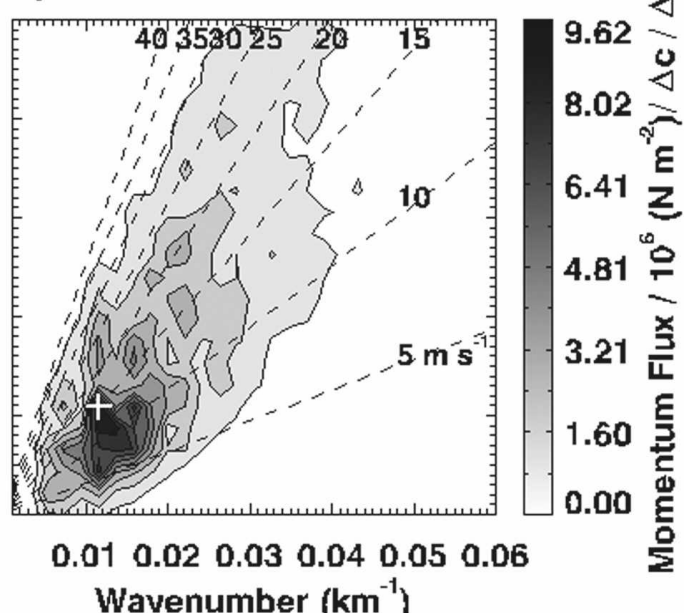

FIG. 6. Event momentum flux plotted with respect to wavenumber and intrinsic frequency for the (a) tropical storm and (b) hurricane. Ground-relative phase speed contours in $\mathrm{m} \mathrm{s}^{-1}$ are shown as dashed lines. A white cross shows the location of the maximum EMF and corresponding intrinsic frequency and wavenumbers are used to calculate a dominant vertical wavenumber with the dispersion relation.

ture at $20 \mathrm{~km}$ becomes easily visible in the model. Fluctuations in vertical velocity are at their strongest at 1712 UTC; this is the time that is used for the wavelet analysis. At this time, the largest perturbations have ampli- tudes for $u^{\prime}, v^{\prime}$, and $w^{\prime}$ of $0.89,1.4$ and $0.22 \mathrm{~m} \mathrm{~s}^{-1}$ respectively. The waves from this event begin to weaken at the $20-\mathrm{km}$ altitude by 1751 UTC.

Wavelet analysis is performed along the dashed line

TABLE 2. Wave characteristics from wavelet and Fourier analysis compared. For the wavelet analysis the wave directions are taken from the source analysis. The wind in the direction of traveling waves $\bar{u}_{H}$ is the wind associated with the dominant waves found over the path at $15-25 \mathrm{~km}$ in the direction of dominant travel and is a weighted average by the dominant momentum flux. The wave propagation $\phi$ is relative to the ground in degrees counterclockwise $(\mathrm{CCW})$ from east.

\begin{tabular}{|c|c|c|c|c|}
\hline & \multicolumn{2}{|c|}{ Wavelet analysis } & \multicolumn{2}{|c|}{ Fourier analysis } \\
\hline & Tropical storm & Hurricane & Tropical storm & Hurricane \\
\hline$\lambda_{H}$ & $31 \mathrm{~km}$ & $37 \mathrm{~km}$ & $85 \mathrm{~km}$ & $86 \mathrm{~km}$ \\
\hline$\lambda_{Z}$ & $7.6 \mathrm{~km}$ & $6.5 \mathrm{~km}$ & $5.5 \mathrm{~km}$ & $4.0 \mathrm{~km}$ \\
\hline $\bar{u}_{H}$ & $-3.72 \mathrm{~m} \mathrm{~s}^{-1}$ & $-1.71 \mathrm{~m} \mathrm{~s}^{-1}$ & $-0.9 \mathrm{~m} \mathrm{~s}^{-1}$ & $-0.3 \mathrm{~m} \mathrm{~s}^{-1}$ \\
\hline$\phi$ & $319.6^{\circ}$ & $301^{\circ}$ & $325^{\circ}$ & $305^{\circ}$ \\
\hline$\alpha$ & $76.3^{\circ}$ & $80.1^{\circ}$ & $86.3^{\circ}$ & $87.3^{\circ}$ \\
\hline$\hat{\omega}$ & $5.57 \times 10^{-3} \mathrm{~s}^{-1}$ & $4.05 \times 10^{-3} \mathrm{~s}^{-1}$ & $1.52 \times 10^{-3} \mathrm{~s}^{-1}$ & $1.09 \times 10^{-3} \mathrm{~s}^{-1}$ \\
\hline$T$ & $19 \mathrm{~min}$ & $26 \mathrm{~min}$ & $69 \mathrm{~min}$ & $96 \min$ \\
\hline$\hat{c}_{H}$ & $27.5 \mathrm{~m} \mathrm{~s}^{-1}$ & $23.8 \mathrm{~m} \mathrm{~s}^{-1}$ & $20.6 \mathrm{~m} \mathrm{~s}^{-1}$ & $14.9 \mathrm{~m} \mathrm{~s}^{-1}$ \\
\hline$\hat{c}_{Z}$ & $6.7 \mathrm{~m} \mathrm{~s}^{-1}$ & $4.2 \mathrm{~m} \mathrm{~s}^{-1}$ & $1.3 \mathrm{~m} \mathrm{~s}^{-1}$ & $0.7 \mathrm{~m} \mathrm{~s}^{-1}$ \\
\hline$c_{H}^{\text {ground }}$ & $23.7 \mathrm{~m} \mathrm{~s}^{-1}$ & $22.1 \mathrm{~m} \mathrm{~s}^{-1}$ & $19.6 \mathrm{~m} \mathrm{~s}^{-1}$ & $14.6 \mathrm{~m} \mathrm{~s}^{-1}$ \\
\hline$c_{g_{H}}$ & $22.2 \mathrm{~m} \mathrm{~s}^{-1}$ & $21.4 \mathrm{~m} \mathrm{~s}^{-1}$ & $19.6 \mathrm{~m} \mathrm{~s}^{-1}$ & $14.5 \mathrm{~m} \mathrm{~s}^{-1}$ \\
\hline$c_{g_{Z}}$ & $6.3 \mathrm{~m} \mathrm{~s}^{-1}$ & $4.0 \mathrm{~m} \mathrm{~s}^{-1}$ & $1.3 \mathrm{~m} \mathrm{~s}^{-1}$ & $0.7 \mathrm{~m} \mathrm{~s}^{-1}$ \\
\hline$\left|\mathbf{c}_{g}\right|$ & $23.0 \mathrm{~m} \mathrm{~s}^{-1}$ & $21.8 \mathrm{~m} \mathrm{~s}^{-1}$ & $19.6 \mathrm{~m} \mathrm{~s}^{-1}$ & $14.5 \mathrm{~m} \mathrm{~s}^{-1}$ \\
\hline MF & $0.01 \mathrm{~N} \mathrm{~m}^{-1}$ (local max) & $0.02 \mathrm{~N} \mathrm{~m}^{-1}$ (local max) & $8.2 \times 10^{-5} \mathrm{~N} \mathrm{~m}^{-1}(\mathrm{IMF})$ & $8.1 \times 10^{-4} \mathrm{~N} \mathrm{~m}^{-1}(\mathrm{IMF})$ \\
\hline
\end{tabular}


TABLE 3. Fourier analysis results compared for NE, NW, SW and SE quadrants. Propagation directions are given in degrees CCW from east.

\begin{tabular}{|c|c|c|c|c|c|c|c|c|}
\hline \multirow[b]{2}{*}{ Quadrant } & \multicolumn{4}{|c|}{ Tropical storm } & \multicolumn{4}{|c|}{ Hurricane } \\
\hline & NE & NW & SW & SE & $\mathrm{NE}$ & NW & SW & SE \\
\hline$\%$ total MF & $50 \%$ & $30 \%$ & $7 \%$ & $13 \%$ & $2 \%$ & $27 \%$ & $19 \%$ & $52 \%$ \\
\hline$c_{H}$ & $13 \mathrm{~m} \mathrm{~s}^{-1}$ & $25 \mathrm{~m} \mathrm{~s}^{-1}$ & $32 \mathrm{~m} \mathrm{~s}^{-1}$ & $9 \mathrm{~m} \mathrm{~s}^{-1}$ & $9 \mathrm{~m} \mathrm{~s}^{-1}$ & $13 \mathrm{~m} \mathrm{~s}^{-1}$ & $10 \mathrm{~m} \mathrm{~s}^{-1}$ & $7 \mathrm{~m} \mathrm{~s}^{-1}$ \\
\hline$\lambda_{H}$ & $43 \mathrm{~km}$ & $91 \mathrm{~km}$ & $152 \mathrm{~km}$ & $65 \mathrm{~km}$ & $67 \mathrm{~km}$ & $94 \mathrm{~km}$ & $94 \mathrm{~km}$ & $67 \mathrm{~km}$ \\
\hline$\%$ total rain water & $47 \%$ & $48 \%$ & $1 \%$ & $4 \%$ & $49 \%$ & $45 \%$ & $3 \%$ & $3 \%$ \\
\hline Propagation direction & $40^{\circ}$ & $185^{\circ}$ & $225^{\circ}$ & $345^{\circ}$ & $325^{\circ}$ & $145^{\circ}$ & $280^{\circ}$ & $315^{\circ}$ \\
\hline
\end{tabular}

in Fig. 7c, which is approximately perpendicular to lines of constant phase and through the convective source. Figure 8 shows a vertical cross section of the vertical velocity along this line at 1712 UTC. The wave can be seen as alternating positive and negative values propagating upward from the upper troposphere to the southeast of the source region.

The complex valued Morlet wavelet is used as the "mother wavelet" in the wavelet transform. The Morlet wavelet is a suitable choice for geophysical applications because it allows for the decomposition of a signal by using a particular wavelet function to construct a picture of the wave amplitude within the signal as a function of position and wavelet scale (Torrence and Compo 1998, Weng and Lau 1994). The results of the wavelet transform performed on $u_{L}^{\prime}$ and $w^{\prime}$ are given by $U_{L}$ and $W$, where $u_{L}^{\prime}$ is the horizontal velocity perturbation component along the dashed line, which is the wave propagation direction. The cospectra of these results are given by the real part of $U_{L}$ multiplied by the conjugate of $W$. The Morlet is a continuous wavelet transform that is not energy conserving. We impose
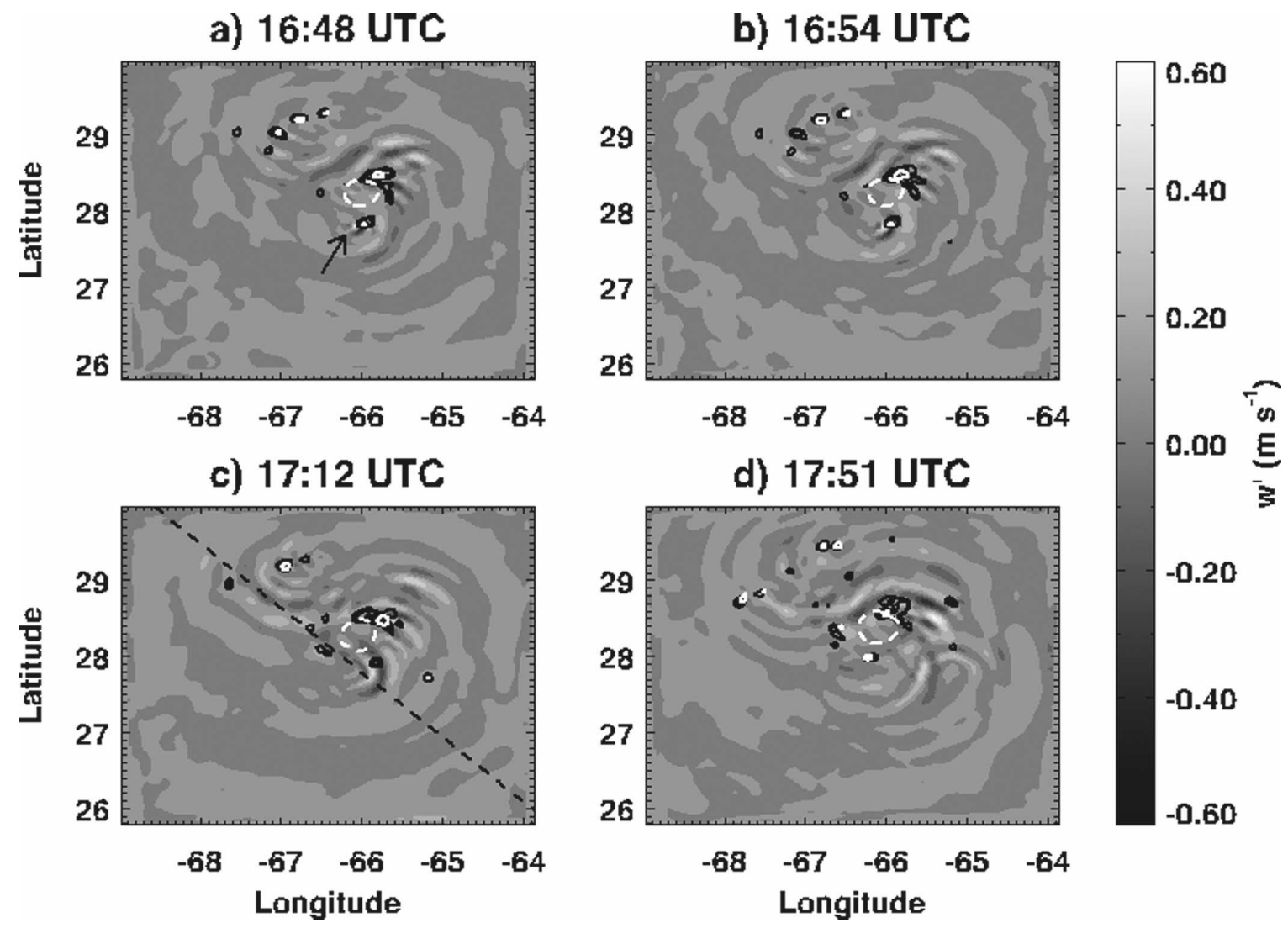

FIG. 7. Snapshots of storm activity during the tropical storm case. The suggested source is indicated by an arrow. A dashed white contour outlines the storm eye. Significant rainfall is shown with black contours where the outer contour represents $25 \mathrm{~mm} \mathrm{hr}^{-1}$. The white contours are $4 \mathrm{~m} \mathrm{~s}^{-1}$ vertical velocities averaged from $5-10 \mathrm{~km}$. Shaded contours of vertical velocity are at a $20-\mathrm{km}$ altitude. Wavelet analysis is performed along the black dashed line. 


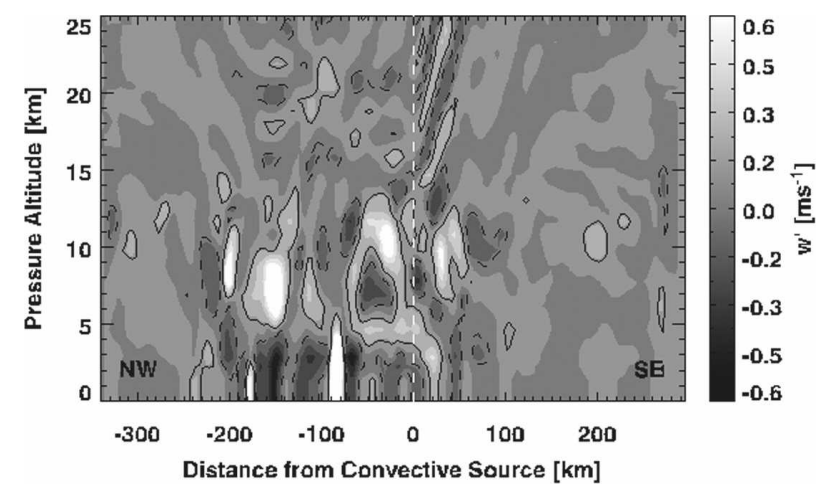

FIG. 8. Vertical velocity perturbations in $\mathrm{m} \mathrm{s}^{-1}$ along the line of analysis for the tropical storm case at 1712 UTC. Positive winds are upward and negative winds are downward.

momentum conservation via a normalizing factor. The cospectra are therefore calculated by

$$
\operatorname{Co}(U W)=\frac{\sum_{x}\left|u_{L}^{\prime} w^{\prime}\right|}{\sum_{k}\left|U_{L} W^{*}\right|} \operatorname{Re}\left\{U_{L} W^{*}\right\} .
$$

The momentum flux is then calculated using the resulting cospectra and the mean density of the corresponding altitude:

$$
\mathrm{MF}=\frac{1}{2} \overline{\rho_{0}} \operatorname{Co}(U W)
$$

Figure 9 shows momentum flux along the cross section at a height of $20 \mathrm{~km}$ integrated over horizontal wavelengths of $15-300 \mathrm{~km}$. The wavelet analysis gives a localized view of gravity wave activity. At a single moment in time and at a location along the dashed line $r$

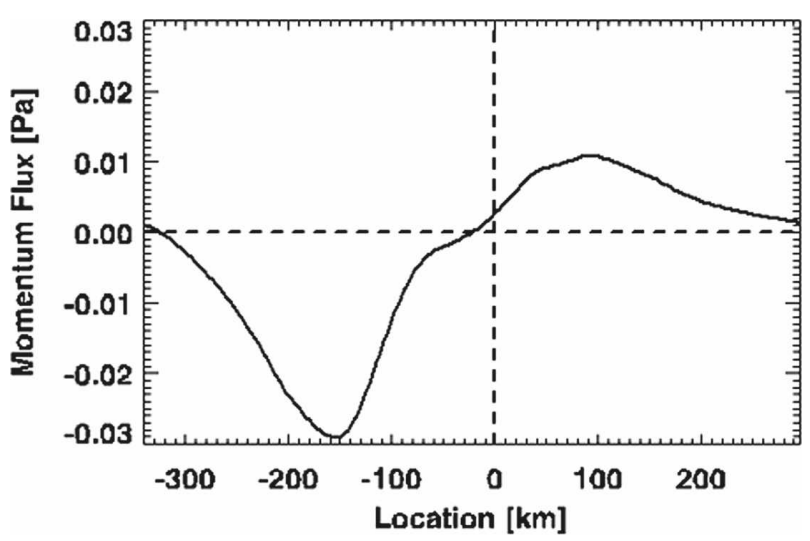

FIG. 9. Momentum flux at an altitude of $20 \mathrm{~km}$ integrated over 15-300 km along the analysis line for the tropical storm case. Positive momentum fluxes represent southeastward fluxes and negative momentum fluxes represent northwestward fluxes. and altitude $z$, a momentum flux spectrum with corresponding wavelengths is found. An average dominant wavelength $\bar{\lambda}_{\mathrm{dom}}$ is found by calculating the average of the wavelength corresponding to the maximum momentum flux $\lambda_{\mathrm{MF}_{\mathrm{MAX}}}(r, z)$, weighted by that maximum momentum flux $\operatorname{MF}_{\operatorname{MAX}}(r, z)$; that is,

$$
\bar{\lambda}_{\mathrm{dom}}=\frac{\sum_{r} \sum_{z}\left(\lambda_{\left.\mathrm{MF}_{\mathrm{MAX}} \mathrm{MF}_{\mathrm{MAX}}\right)}\right.}{\sum_{r} \sum_{z} \mathrm{MF}_{\mathrm{MAX}}},
$$

where $r>0 \mathrm{~km}$ along the path of analysis and $z$ includes the 14 altitude layers between 15 and $25 \mathrm{~km}$.

We also perform wavelet analysis in the vertical to compute vertical wavelength and momentum flux versus height, and an overall average dominant vertical wavelength is calculated in an analogous way to the horizontal wavelength. The maximum momentum flux is $0.01 \mathrm{~N} \mathrm{~m}^{-2}$ and occurs $94 \mathrm{~km}$ southeast of the source. A dominant vertical wavelength of $7.6 \mathrm{~km}$ and dominant horizontal wavelength of $31 \mathrm{~km}$ are found to be associated with the maximum fluxes to the southeast of the source.

We next use linear gravity wave theory together with the dominant vertical and horizontal wavelengths found to determine further characteristics associated with the wave event. The intrinsic frequency $\hat{\omega}$ is the frequency that would be observed in a frame of reference moving with the background wind; it is given by the dispersion relation for gravity waves

$$
\hat{\omega}^{2}=\frac{N^{2} k_{H}^{2}+f^{2}\left(m^{2}+\frac{1}{4 H^{2}}\right)}{m^{2}+k_{H}^{2}+\frac{1}{4 H^{2}}},
$$

where the horizontal wavenumber is $k_{H}$ and the vertical wavenumber is $m$. The Coriolis parameter $f$ is a measure of the effect of the earth's rotation and is $0.64 \times$ $10^{-4}$ to $0.92 \times 10^{-4} \mathrm{~s}^{-1}$ for latitudes studied in this model. The buoyancy frequency $N$, a measure of the static stability in the atmosphere, has a value of $0.02-$ $0.025 \mathrm{~s}^{-1}$ in the model at $15-25 \mathrm{~km}$. The scale height $H$ is a function of temperature and is typically $7 \mathrm{~km}$ in the stratosphere.

The horizontal and vertical intrinsic phase speeds can be found after the intrinsic frequency is determined with

$$
\begin{aligned}
& \hat{c}_{H}=\frac{\hat{\omega}}{k_{H}} \text { and } \\
& \hat{c}_{Z}=\frac{\hat{\omega}}{m} .
\end{aligned}
$$



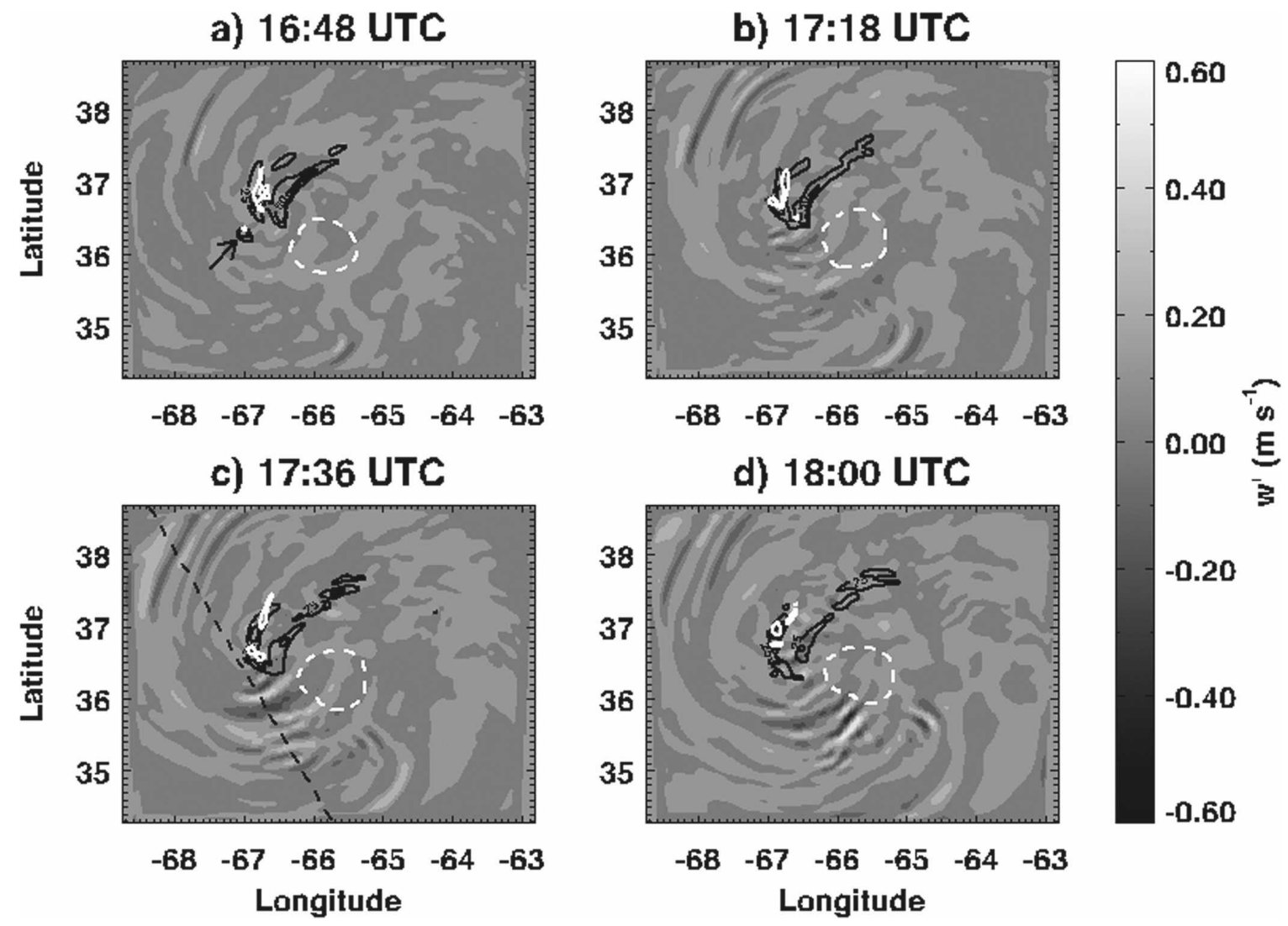

FIG. 10. Snapshots of storm activity as in Fig. 7, but during the hurricane case.

The ground-relative phase speed $c_{H}^{\text {ground }}$ is given by the horizontal intrinsic frequency $\hat{c}_{H}$ and the observed background horizontal wind component $\bar{u}_{H}$ at the altitude of the wave and in the direction of wave propagation:

$$
\hat{c}_{H}=c_{H}^{\text {ground }}-\bar{u}_{H}
$$

Vertical shear in the horizontal wind in the stratosphere is weak in the model. Wind magnitudes are less than $5 \mathrm{~m} \mathrm{~s}^{-1}$.

The angle between lines of constant phase and the vertical $\alpha$ can be inferred from the approximation

$$
\alpha \approx \cos ^{-1}\left(\frac{\hat{\omega}}{N}\right)
$$

The group velocity $c_{g}\left(k_{H}, m\right)$ describes the energy transport related to the wave:

$$
\mathbf{c}_{g}=\left(\bar{u}_{H}, 0\right)+\frac{\left[k_{H}\left(N^{2}-\hat{\omega}^{2}\right),-m\left(\hat{\omega}^{2}-f^{2}\right)\right]}{\hat{\omega}\left(k_{H}^{2}+m^{2}+\frac{1}{4 H^{2}}\right)} .
$$

In cases currently under study, the wave packet is observed to propagate upward. This implies that the vertical component of the group velocity is positive $\left(c_{g z}>\right.$ $0)$. Because this is a gravity wave, $c_{g z}>0$ determines that $m<0$ when using these equations. For atmospheric gravity waves on the scales observed in this study, the horizontal component of the group velocity is expected to be close in magnitude to the groundrelative phase speed.

For this tropical storm case, the group velocity is found to be $23.0 \mathrm{~m} \mathrm{~s}^{-1}$ traveling at an angle $76.3^{\circ}$ from vertical. The intrinsic frequency is calculated at $5.57 \times 10^{-3} \mathrm{~s}^{-1}$, which gives a period of $19 \mathrm{~min}$. The waves are observed to have a ground-relative phase speed of $23.7 \mathrm{~m} \mathrm{~s}^{-1}$. These wave characteristics are shown in Table 2 and are compared to results from the Fourier analysis.

Figures 10-12 show the identification of a wave event and wavelet analysis for the hurricane case. In Fig. 10a, a source is identified that is relatively short-lived, isolated, and intense, making it a good candidate for study. The source has turned off in Fig. 10b after 20 min have passed, and the waves created by this source are beginning to appear at the $20-\mathrm{km}$ altitude. Figure $10 \mathrm{c}$ shows 


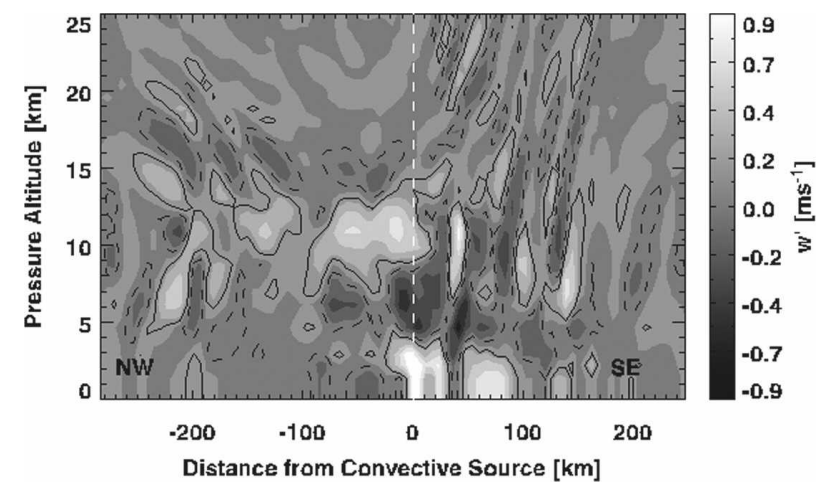

FIG. 11. Vertical wind perturbations in $\mathrm{m} \mathrm{s}^{-1}$ along the line of analysis for the hurricane case at 1648 UTC.

a snapshot of the vertical velocity perturbations $w^{\prime}$ at 1736 UTC. At this time, maximum amplitudes for $u^{\prime}, v^{\prime}$, and $w^{\prime}$ are $0.59,1.60$, and $0.20 \mathrm{~m} \mathrm{~s}^{-1}$, respectively, with a significant wave packet just to the southeast of the source at $36.3^{\circ} \mathrm{N}, 67.0^{\circ} \mathrm{W}$. Wavelet analysis is performed along the dashed line through the convective source and perpendicular to the wave phase fronts. The waves appear to turn with the cyclonic flow in Fig. 10d. Figure 11 shows a vertical cross section of vertical velocity along the dashed line from the northwest to the southeast at 1736 UTC.

Figure 12 shows a peak in momentum flux associated with the wave event of $0.02 \mathrm{~N} \mathrm{~m}^{-2}$ approximately $66 \mathrm{~km}$ to the southeast of the source. The dominant horizontal wavelength found to be associated with the maximum fluxes along this analysis path to the southeast of the source is $37 \mathrm{~km}$ and the dominant vertical wavelength is $6.5 \mathrm{~km}$. The group velocity is found to be $21.8 \mathrm{~m} \mathrm{~s}^{-1}$ traveling at an angle $80.1^{\circ}$ from vertical. The waves are observed to move with a ground-relative phase speed of $22.1 \mathrm{~m} \mathrm{~s}^{-1}$. The intrinsic frequency is $4.05 \times 10^{-3} \mathrm{~s}^{-1}$, which gives a period of $26 \mathrm{~min}$.

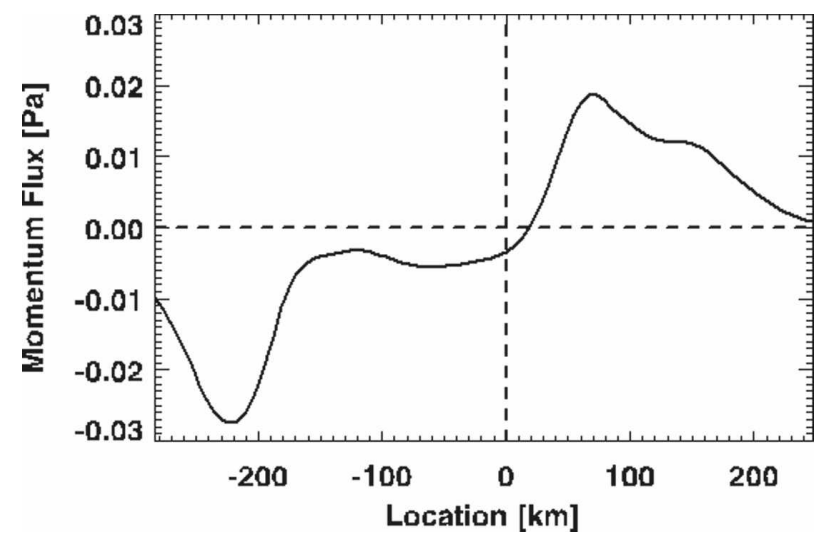

FIG. 12. Momentum flux at $20 \mathrm{~km}$ integrated over horizontal wavelengths of $15-300 \mathrm{~km}$ with respect to distance from the source in $\mathrm{km}$ for the hurricane case.

\section{Source analysis}

By studying animations of $w^{\prime}$ at an altitude of $20 \mathrm{~km}$ overlain with contours of significant updrafts in the troposphere, we note that the large-amplitude wave events tend to follow the motion of the most convectively active regions within the storm. The movement of these sources may be important to determining the main mechanisms at work in wave generation. Parameterizations of wave generation by convection (e.g., Chun and Baik 1998; Beres et al. 2004) specify gravity wave properties based on properties of the convective heating and the background wind profile. The isolated wave events highlighted in section 5 show very anisotropic wave fields above these sources despite only weak wind shear. In this section, we investigate the origin of this anisotropy and the ability of the parameterizations to capture it. The average locations of the sources identified in section 5 are found and their movement in time is tracked over $10 \mathrm{~min}$ to determine the velocity of the sources. Horizontal wind velocities at several altitudes of interest are also averaged over this same area and time. Altitudes of interest include the top of the convective heating, the $20-\mathrm{km}$ wave analysis altitude, and the 700-hPa level $(2.8 \mathrm{~km})$.

Wave generation via an obstacle effect gives highly anisotropic wave propagation. For this mechanism, the dominant direction in which the waves are expected to travel is given by the vector $-\mathbf{v}_{f}$, found by subtracting source velocity vector $\mathbf{v}_{S}$ from the wind vector at the top of the heating profile $\mathbf{v}\left(z_{\mathrm{TOP}}\right)$. In deep convection embedded in shear, it is difficult to choose the altitude of convective heating that is relevant to wave generation. We choose the top of the heating profile to be the altitude where velocities in the updraft region go to zero and are found to be 14.7 and $9.7 \mathrm{~km}$ for the tropical storm and hurricane source cases, respectively, in this study. The winds at this altitude are important to determining the wave momentum flux in the parameterizations applied in GCMs (Beres et al. 2004; Chun and Baik 1998). The parameterizations also assume that the motion of the unresolved small-scale heat sources in global models moves with the speed and direction of the 700-hPa wind $\mathbf{v}_{700}$, so we also compare $\mathbf{v}_{S}$ to $\mathbf{v}_{700}$.

For waves generated by the obstacle effect, the frequency of waves created in a frame moving with the heating $\omega_{S}$ is zero. The intrinsic frequency $\hat{\omega}$ at a given altitude is defined as the frequency moving in the frame relative to the ground $\omega_{0}$, minus the wind vector at the altitude of interest dotted into the wavenumber vector; that is,

$$
\hat{\omega}(z)=\omega_{0}-\mathbf{v}(z) \cdot \mathbf{k}
$$


(a)

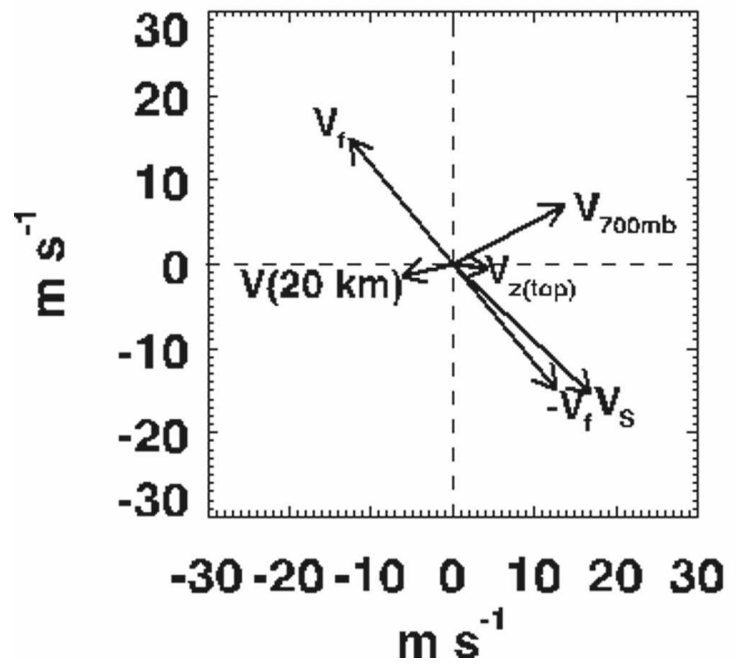

(b)

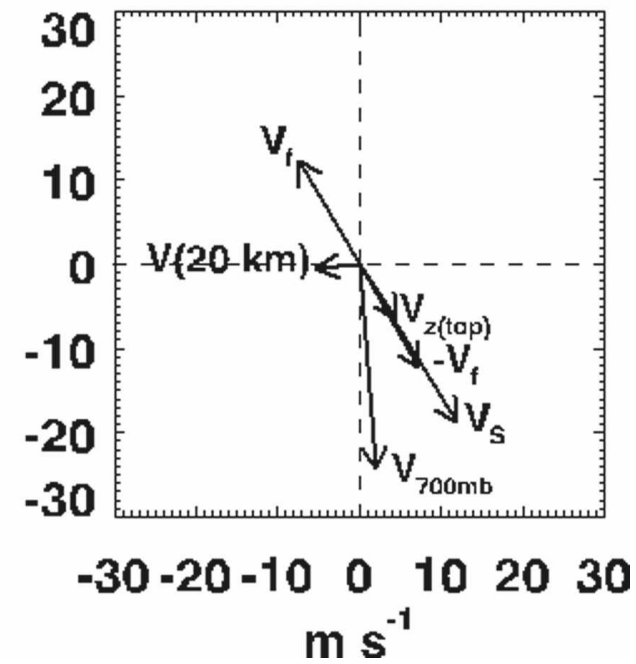

FIG. 13. Source analysis vectors for the (a) tropical storm and (b) hurricane.

The source will generate waves at a frequency, given by

$$
\omega_{0}=\omega_{S}-\left[\mathbf{v}\left(z_{\mathrm{TOP}}\right)-\mathbf{v}_{S}\right] \cdot \mathbf{k} .
$$

The intrinsic frequency at a specific altitude $z$ can then be found by

$$
\hat{\omega}(z)=-\left[\mathbf{v}\left(z_{\mathrm{TOP}}\right)-\mathbf{v}_{S}\right] \cdot \mathbf{k}-\mathbf{v}(z) \cdot \mathbf{k} .
$$

The vertical wavenumber of the expected waves at a specific altitude may be calculated with an approximation of the dispersion relation. Waves investigated in this study have midrange intrinsic frequencies and, in general, $m^{2} \gg\left(1 / 4 H^{2}\right), \hat{\omega} \gg f$, and $m \gg k_{H}$; therefore. Eq. (8) may be simplified and rearranged for the vertical wavenumber $m$ as shown:

$$
m=\frac{N k_{H}}{\hat{\omega}} .
$$

If the obstacle effect is generating the waves, the phase speed of the waves relative to the ground is given by $\left|\mathbf{v}_{S}\right|$. The propagation direction and intrinsic phase speed of these waves is given by $-\mathbf{v}_{f}$ for a steady heat source in time. Vector plots in Fig. 13 show the wind velocities of interest at the source, the source velocity $\mathbf{v}_{S}$, and the expected wave propagation direction $-\mathbf{v}_{f} /$ $\left|\mathbf{v}_{f}\right|$. These values are also listed in Table 4 for comparison. In these cyclonic storm examples, the $700-\mathrm{hPa}$ wind vectors do not appear to be representative of the motion of convectively active regions, represented as a heat source in parameterization applications (Beres et al. 2005). The direction of source movement compared to the winds at $700 \mathrm{hPa}$ is very different in both cases; however, the magnitude of the hurricane case $700-\mathrm{hPa}$ wind speeds is comparable to the source speed at 24.4 and $22.1 \mathrm{~m} \mathrm{~s}^{-1}$, respectively. In the tropical storm case, the source is moving at $22.9 \mathrm{~m} \mathrm{~s}^{-1}$, which is about 8 $\mathrm{m} \mathrm{s}^{-1}$ faster than the winds at $700 \mathrm{hPa}\left(15.3 \mathrm{~m} \mathrm{~s}^{-1}\right)$. Winds at $20 \mathrm{~km}$ are no longer affected by the storm but are uniformly westward at about $5-7 \mathrm{~m} \mathrm{~s}^{-1}$. The peak wave amplitudes follow the source and the waves propagate away from the source in the direction of $-\mathbf{v}_{f}$. The dominant wave propagation directions found with Fourier analysis (Table 2) are similar to the directions found in the southeast quadrant for each case.

\section{Discussion}

The results of these simulations can be used to investigate the mechanisms that are playing an important

TABLE 4. Results from source analysis show the speed and direction (CCW from east) of source and wind velocities. The top of

\begin{tabular}{|c|c|c|c|c|}
\hline \multicolumn{5}{|c|}{ Source/Wind analysis } \\
\hline & \multicolumn{2}{|c|}{ Tropical storm } & \multicolumn{2}{|c|}{ Hurricane } \\
\hline & Speed & Direction & Speed & Direction \\
\hline $\mathbf{v}_{S}$ & $22.9 \mathrm{~m} \mathrm{~s}^{-1}$ & $312.2^{\circ}$ & $22.1 \mathrm{~m} \mathrm{~s}^{-1}$ & $302.4^{\circ}$ \\
\hline $\mathbf{v}\left(z_{\mathrm{TOP}}\right)$ & $4.4 \mathrm{~m} \mathrm{~s}^{-1}$ & $352.8^{\circ}$ & $7.9 \mathrm{~m} \mathrm{~s}^{-1}$ & $305.0^{\circ}$ \\
\hline $\mathbf{v}(20 \mathrm{~km})$ & $6.3 \mathrm{~m} \mathrm{~s}^{-1}$ & $192.3^{\circ}$ & $5.3 \mathrm{~m} \mathrm{~s}^{-1}$ & $185.0^{\circ}$ \\
\hline $\mathbf{v}_{700}$ & $15.3 \mathrm{~m} \mathrm{~s}^{-1}$ & $27.3^{\circ}$ & $24.4 \mathrm{~m} \mathrm{~s}^{-1}$ & $274.6^{\circ}$ \\
\hline$-\mathbf{v}_{f}$ & $19.5 \mathrm{~m} \mathrm{~s}^{-1}$ & $319.6^{\circ}$ & $14.3 \mathrm{~m} \mathrm{~s}^{-1}$ & $301.0^{\circ}$ \\
\hline
\end{tabular}
the convection $z_{\mathrm{TOP}}$ is $14.6 \mathrm{~km}$ for the tropical storm and $9.7 \mathrm{~km}$ for the hurricane case. These are shown as vectors in Fig. 13. 
role in the generation of waves from the active storm environment. In this section, the three major mechanisms - deep heating, mechanical oscillator, and the obstacle effect-are discussed in terms of theoretical wave spectral properties from each mechanism and compared to the results of the spectral analysis of the model.

In the absence of substantial background wind, the deep heating mechanism predicts the gravity wave response to be governed by the frequency and horizontal and vertical scales of the diabatic heating within the storm (Holton et al. 2002). In general, the mechanism results in peak wave excitation at vertical wavelengths 2 to 4 times the depth of the heating, depending on the horizontal and temporal scales of the heating. As waves propagate vertically across the tropopause, their vertical wavelengths are refracted to half their original value, and vertical wind shears will cause additional refraction. The range of wave phase speeds associated with the deep heating mechanism can be estimated by assuming wave generation in the troposphere with vertical wavelengths $\lambda_{Z} \sim 2 D$ to $4 D$, where $D$ is the depth of heating. Using (17) and (9), we can estimate $\hat{c}_{H}=$ $N \lambda_{Z} / 2 \pi$. Based on Fig. 3 , we choose $D=12 \mathrm{~km}$ as a lower limit and $N \sim 0.01 \mathrm{~s}^{-1}$ to estimate $\hat{c}_{H}=36-76$ $\mathrm{m} \mathrm{s}^{-1}$. Here, $\hat{c}_{H}$ is the phase speed in the frame of reference moving with the heating. The cyclonic motion of the heating sources near the eyewall estimated in section 6 was $\sim 22 \mathrm{~m} \mathrm{~s}^{-1}$. Vertical wind shear above the heating is weak at about $5 \mathrm{~m} \mathrm{~s}^{-1}$. Using these values to shift $\hat{c}_{H}$ to the ground based frame of reference gives the wide range of ground-relative phase speeds of 9 to $103 \mathrm{~m} \mathrm{~s}^{-1}$. Re-examining Fig. 4 suggests that the deep heating mechanism is likely responsible for the highphase-speed tail of the spectrum and may be responsible for a substantial portion of the broad peak in phase speeds below $25 \mathrm{~m} \mathrm{~s}^{-1}$.

In the oscillator mechanism, a parcel of air rises to its level of neutral buoyancy and oscillates at that buoyancy frequency. It is this oscillation that generates a propagating wave (Lane et al. 2001). Presumably the parcel is drifting with the winds at this level, so the frequency of oscillation is intrinsic frequency. The intrinsic frequencies that can be generated by this mechanism will be the local moist buoyancy frequencies $N_{m}$, typically in a layer in the upper troposphere (Durran and Klemp 1982). The range of moist buoyancy frequencies observed in our simulations between 10 and $15 \mathrm{~km}$ is $0.022-0.028 \mathrm{~s}^{-1}$. To examine whether waves near this frequency are prominent in the model, we must convert the intrinsic frequency to ground-based frequencies and compare the result to the spectrum in Fig. 6 . Winds at this level are between 4 and $8 \mathrm{~m} \mathrm{~s}^{-1}$.
Dominant horizontal wavelengths were found to be on the order of $30 \mathrm{~km}$ from the wavelet analysis. The ground-relative frequencies associated with the oscillator mechanism would then be expected to be $N_{m} \pm$ $\mathbf{v}\left(z_{\mathrm{TOP}}\right) \cdot \mathbf{k}$, where \pm refers to waves propagating with or against the flow. We estimate these frequencies to be $0.0217-0.0283 \mathrm{~s}^{-1}$ relative to the ground. From Fig. 6 one can see that momentum fluxes in this range of frequencies are very small, suggesting that the oscillator mechanism is not playing a significant role in this simulation.

We note that the largest wave events tend to follow the motion of the largest heating events, which are presented here as the most convectively active regions. This suggests the possibility that the heat sources are acting as an obstacle to the flow and generating waves via the obstacle effect. In direct analogy to topographic wave generation, the wave amplitude and propagation direction depends on the height of the mountain and the wind vector relative to the mountain. In the convective analogy, the mountain also moves and the phase speed of the wave is equal to the motion of the obstacle. Taking into account the movement of the "mountain" and the wind at the top of the convection, we were able to predict the wave direction at significant sources for both the tropical storm and hurricane cases. Deep convection generates quasi-stationary waves relative to the source by this mechanism (Beres et al. 2002; Moustaoui et al. 2004; Pfister et al. 1993). In section 6, the source speeds for two isolated events were found to be similar to the ground-relative phase speeds of the waves they generated. For the tropical storm case, these speeds are $22.9 \mathrm{~m} \mathrm{~s}^{-1}$ and $23.7 \mathrm{~m} \mathrm{~s}^{-1}$, respectively. The source speed and wave ground-relative phase speed found in the hurricane case are equal at $22.1 \mathrm{~m} \mathrm{~s}^{-1}$. Rain events further from the storm eye are likely associated with slower-moving heat sources that would populate the peak in the spectrum (Fig. 4) with phase speeds $10-20 \mathrm{~m} \mathrm{~s}^{-1}$ via the obstacle mechanism.

Often, the maximum rainfall is found in the leading side of a tropical cyclone and this region moves to the right front quadrant as the overall storm travel speed increases (Frank 1977; Lonfat et al. 2004). This would be the north side and northeast quadrant for the simulations in this study, and the major rainfall regions are found to be on the north side of the storm for both cases. In this simulation we found that the greatest momentum fluxes do not necessarily align with the rainiest regions, but rather occur within the regions with the strongest winds within the storm. As a general rule, the right side of a storm is said to be the most dangerous; with significant storm surge, tornadoes, and greater maximum winds. Hurricane wind speed and the speed 
of the larger atmospheric flow (storm movement) add as they are traveling in the same direction in this quadrant (Novlan and Gray 1974; Pore 1957). It is surmised that more intense winds within the storm would cause heat sources within this region to move faster. In the model, the north right quadrant also has significant sources represented by nearly $50 \%$ of the rainfall. Because wave activity generated by the obstacle effect mechanism would have these sources moving at greater relative speeds on the right side of the storm, one would expect stronger momentum fluxes to coincide with this side of the storm. In the tropical storm case, the strongest fluxes are found to be in the northeast quadrant, whereas in the hurricane case they are in the southeast quadrants, both on the right side of the storm.

An interesting phenomenon is observed in animations of vertical velocities in the model. Waves emanating from a source begin to propagate outward with phase fronts perpendicular to a radial path from the source; but as they travel outward they turn in the direction of the cyclonic flow with the wave fronts oriented like spokes from the center of the storm. It has been observed that winds in the upper part of convection can enhance waves propagating opposite to the direction of the shear (Beres et al. 2004). In a tropical cyclone, air spirals inward and cyclonically toward the center of the storm near the bottom and outward, an- ticyclonically, near the top. This inherent shear may be the mechanism that creates the wave patterns radial to the storm center that are often seen in satellite cloud imagery of tropical cyclones (e.g., see the Advanced Very High Resolution Radiometer (AVHRR) image of Humberto in Heymsfield et al. 2006). This hypothesis needs further testing with ray tracing techniques. It has been demonstrated that the winds are steering the sources and these same winds would hinder waves propagating in a clockwise direction via a wind filtering mechanism. The obstacle effect mechanism would produce wave phase fronts perpendicular to this azimuthal motion of the tropical storm winds that would therefore extend radially from the storm center.

A simple calculation of the momentum flux in the subtropical lower stratosphere due to hurricanes every year can be done as an exercise. Using Tables 2 and 3, the average IMF from a hurricane during its lifetime has an absolute value of $8.1 \times 10^{-4} \mathrm{~N} \mathrm{~m}^{-2}$; about $50 \%$ of this value is eastward flux. We focus on eastwardpropagating waves because they will contribute to the forcing of the westerly phase of the QBO observed during this summer of 2001. Using Webster et al. (2005), we estimate that there are a total of approximately 475 hurricane days per year (365 days) across the globe in the Northern Hemisphere. The average zonal mean hurricane flux is then calculated as

$$
\left(8.1 \times 10^{-4} \mathrm{~N} \mathrm{~m}^{-2}\right) 0.5\left(\frac{\frac{3}{4} 475 \text { days }}{365 \text { days }}\right)\left(\frac{5^{\circ}}{360^{\circ}}\right)=5 \times 10^{-6} \mathrm{~N} \mathrm{~m}^{-2}
$$

where $5^{\circ}$ is the domain size listed to determine the fluxes in Table 2. Manzini and McFarlane (1998) report eastward zonal July momentum fluxes per latitude of $1-2.5 \times 10^{-3} \mathrm{~N} \mathrm{~m}^{-2}$. Fluxes needed to drive the QBO have been estimated at 3-6 $610^{-3} \mathrm{~N} \mathrm{~m}^{-2}$ (Dunkerton 1997; Scaife et al. 2000).

In the above result, the estimated zonal flux is fairly small. These fluxes may be somewhat underestimated. Large-amplitude wave events with short horizontal wavelengths of $30 \mathrm{~km}$ are found in this study. This is near the limit that can be resolved by this model. A model with higher horizontal resolution would resolve shorter horizontal wavelength waves, which may carry additional momentum flux.

\section{Summary and conclusions}

A model study of gravity waves generated by deep convection within a tropical cyclone environment is described. The model is validated with observations of
Humberto by the National Hurricane Center and during the CAMEX-4 experiment in 2001. Analysis of regions of significant latent heating, rainfall, and emanating waves are used to look at the characteristics of the waves observed with this model in the lower stratosphere. In general, the horizontal wavelength spectrum in the model is $15-300 \mathrm{~km}$ and dominant vertical wavelengths ranged from 4 to $8 \mathrm{~km}$. Ground-relative phase speeds corresponding to larger momentum fluxes were $15-24 \mathrm{~m} \mathrm{~s}^{-1}$.

Wave phase speeds are found to be approximately equal to the speed of the moving heat source, which supports the importance of the obstacle effect mechanism for wave generation in these simulations. It is interesting that the largest momentum fluxes are found on the right side of the storm, coinciding with the strongest winds and fastest-moving sources. Waves generated by the deep heating mechanism likely populate the high-phase speed tail of the spectrum and also contribute to the broad peak along with waves generated by 
the obstacle effect. This study shows that a combination of these two mechanisms, including the effects of background winds, may be a simple way to estimate the complex gravity wave spectrum created by convective sources.

Momentum fluxes associated with local events around $20 \mathrm{~km}$ are found to be $0.01-0.03 \mathrm{~N} \mathrm{~m}^{-2}$. Recall that Sato (1993) found local values of $0.04 \mathrm{~N} \mathrm{~m}^{-2}$ at this same altitude for Typhoon Kelly. With Fourier analysis of the near-cloud resolving model simulation of Humberto, an average zonal mean momentum flux of $5 \times$ $10^{-6} \mathrm{~N} \mathrm{~m}^{-2}$ annual average is estimated. This suggests that although hurricanes may be an important localized source for middle atmospheric gravity waves in the subtropics, they are only a small contributor to global forcing.

Acknowledgments. The authors wish to acknowledge Gerry Heymsfield for his assistance with the EDOP data acquired during the CAMEX-4 campaign. This material is based on work supported by the National Science Foundation Physical and Dynamical Meteorology Program under Grants ATM-0234230 and ATM0632378.

\section{REFERENCES}

Alexander, M. J., and L. Pfister, 1995: Gravity wave momentum flux in the lower stratosphere over convection. Geophys. Res. Lett., 22 (15), 2029-2032.

_ J. H. Beres, and L. Pfister, 2000: Tropical stratospheric gravity wave activity and relationships to clouds. J. Geophys. Res., 105 (D17), 22 299-22 309.

_ , P. T. May, and J. H. Beres, 2004: Gravity waves generated by convection in the Darwin area during the Darwin Area Wave Experiment. J. Geophys. Res., 109, D20S04, doi:10.1029/2004JD004729.

Beres, J. H., M. J. Alexander, and J. R. Holton, 2002: Effects of tropospheric wind shear on the spectrum of convectively generated gravity waves. J. Atmos. Sci., 59, 1805-1824.

,$- \ldots$, and $\_, 2004$ : A method of specifying the gravity wave spectrum above convection based on latent heating properties and background wind. J. Atmos. Sci., 61, 324-337.

—, R. R. Garcia, B. A. Boville, and F. Sassi, 2005: Implementation of a gravity wave source spectrum parameterization dependent on the properties of convection in the Whole Atmosphere Community Climate Model (WACCM). J. Geophys. Res., 110, D10108, doi:10.1029/2004JD005504.

Beven, J. L., II, S. R. Stewart, M. B. Lawrence, L. A. Avila, J. L. Franklin, and R. J. Pasch, 2003: Annual summary: Atlantic hurricane season of 2001. Mon. Wea. Rev., 131, 1454-1484.

Chun, H.-Y., and J.-J. Baik, 1998: Momentum flux by thermally induced internal gravity waves and its approximation for large-scale models. J. Atmos. Sci., 55, 3299-3310.

Davis, C. A., and S. Low-Nam, 2001: The NCAR-AFWA tropical cyclone bogussing scheme: A report prepared for the Air Force Weather Agency (AFWA). National Center for At- mospheric Research, 13 pp. [Available online at http:// www.mmm.ucar.edu/mm5/mm5v3/tc-report.pdf.]

Dewan, E. M., and Coauthors, 1998: MSX satellite observations of thunderstorm-generated gravity waves in mid-wave infrared images of the upper stratosphere. Geophys. Res. Lett., 25 (7), 939-942.

Dudhia, J., 1993: A nonhydrostatic version of the Penn StateNCAR mesoscale model: Validation tests and simulation of an Atlantic cyclone and cold front. Mon. Wea. Rev., 121, 1493-1513.

Dunkerton, T. J., 1997: The role of gravity waves in the quasibiennial oscillation. J. Geophys. Res., 102 (D22), $26053-$ 26076.

Durran, D. R., and J. B. Klemp, 1982: On the effects of moisture on the Brunt-Vaisala frequency. J. Atmos. Sci., 39, 21522158.

Fovell, R., D. Durran, and J. R. Holton, 1992: Numerical simulations of convectively generated stratospheric gravity waves. $J$. Atmos. Sci., 49, 1427-1442.

Frank, W. M., 1977: The structure and energetics of the tropical cyclone. Part I: Storm structure. Mon. Wea. Rev., 105, 11191135 .

Fritts, D. C., and M. J. Alexander, 2003: Gravity wave dynamics and effects in the middle atmosphere. Rev. Geophys., 41, 1003, doi:10.1029/2001RG000106.

Giorgetta, M. A., E. Manzini, and E. Roeckner, 2002: Forcing of the quasi-biennial oscillation from a broad spectrum of atmospheric waves. Geophys. Res. Lett., 29, 1245, doi:10.1029/ 2002 GL014756.

Grell, G. A., J. Dudhia, and D. R. Stauffer, 1995: A description of the fifth-generation Penn State/NCAR Mesoscale Model (MM5). NCAR Tech. Note NCAR/TN-398+STR, 138 pp.

Heymsfield, A. J., A. Bansemer, S. L. Durden, R. L. Herman, and T. P. Bui, 2006: Ice microphysics observations in Hurricane Humberto: Comparison with non-hurricane-generated ice cloud layers. J. Atmos. Sci., 63, 288-308.

Heymsfield, G. M., and Coauthors, 1996: The EDOP radar system on the high-altitude NASA ER-2 aircraft. J. Atmos. Oceanic Technol., 13, 795-809.

Holton, J. R., J. H. Beres, and X. Zhou, 2002: On the vertical scale of gravity waves excited by localized thermal forcing. $J$. Atmos. Sci., 59, 2019-2023.

Kakar, R., M. Goodman, R. Hood, and A. Guillory, 2006: Overview of the Convection and Moisture Experiment (CAMEX). J. Atmos. Sci., 63, 5-18.

Kelley, O. A., and J. Stout, 2004: Convective towers in eyewalls of tropical cyclones observed by the TRMM precipitation radar in 1998-2001. Preprints, 20th Conf. on Weather Analysis and Forecasting, Seattle, WA, Amer. Meteor. Soc., P1.43. [Available online at http://ams.confex.com/ams/pdfpapers/ 68522.pdf.]

Kim, S.-Y., H.-Y. Chun, and J.-J. Baik, 2005: A numerical study of gravity waves induced by convection associated with Typhoon Rusa. Geophys. Res. Lett., 32, L24816, doi:10.1029/ 2005 GL024662.

Lane, T. P., M. J. Reeder, and T. L. Clark, 2001: Numerical modeling of gravity wave generation by deep tropical convection. J. Atmos. Sci., 58, 1249-1274.

Lonfat, M., F. D. Marks Jr., and S. S. Chen, 2004: Precipitation distribution in tropical cyclones using the Tropical Rainfall Measuring Mission (TRMM) Microwave Imager: A global perspective. Mon. Wea. Rev., 132, 1645-1660.

Manzini, E., and N. A. McFarlane, 1998: The effect of varying the 
source spectrum of a gravity wave parameterization in a middle atmosphere general circulation model. J. Geophys. Res., 103 (D24), 31 523-31 539.

Moustaoui, M., B. Joseph, and H. Teitelbaum, 2004: Mixing layer formation near the tropopause due to gravity wave-critical level interactions in a cloud-resolving model. J. Atmos. Sci., 61, 3112-3124.

Novlan, D. J., and W. M. Gray, 1974: Hurricane-spawned tornadoes. Mon. Wea. Rev., 102, 476-488.

Pfister, L., W. Starr, R. Craig, and M. Loewenstein, 1986: Smallscale motions observed by aircraft in the tropical lower stratosphere: Evidence for mixing and its relationship to large-scale flows. J. Atmos. Sci., 43, 3210-3225.

— cyclone during the STEP tropical field program: A case study. J. Geophys. Res., 98 (D5), 8611-8638.

Piani, C., D. Durran, M. J. Alexander, and J. R. Holton, 2000: A numerical study of three-dimensional gravity waves triggered by deep tropical convection and their role in the dynamics of the QBO. J. Atmos. Sci., 57, 3689-3702.

Pore, A., 1957: Ocean surface waves produced by some recent hurricanes. Mon. Wea. Rev., 85, 385-392.

Sato, K., 1993: Small-scale wind disturbances observed by the MU radar during the passage of Typhoon Kelly. J. Atmos. Sci., 50, $518-537$.
Scaife, A. A., N. Butchart, C. D. Warner, D. Stainforth, W. Norton, and J. Austin, 2000: Realistic quasi-biennial oscillations in a simulation of the global climate. Geophys. Res. Lett., 27 (21), 3481-3484.

Song, I.-S., and H.-Y. Chun, 2005: Momentum flux spectrum of convectively forced internal gravity waves and its application to gravity wave drag parameterization. Part I: Theory. J. Atmos. Sci., 62, 107-124.

, _ _ , and T. P. Lane, 2003: Generation mechanisms of convectively forced internal gravity waves and their propagation in the stratosphere. J. Atmos. Sci., 60, 1960-1980.

Torrence, C., and G. P. Compo, 1998: A practical guide to wavelet analysis. Bull. Amer. Meteor. Soc., 79, 61-78.

Wang, L., M. J. Alexander, T. P. Bui, and M. J. Mahoney, 2006: Small-scale gravity waves in ER-2 MMS/MTP wind and temperature measurements during CRYSTAL-FACE. Atmos. Chem. Phys., 6, 1091-1104.

Webster, P. J., G. J. Holland, J. A. Curry, and H.-R. Chang, 2005: Changes in tropical cyclone number, duration, and intensity in a warming environment. Science, 309, 1844-1846.

Weng, H., and K.-M. Lau, 1994: Wavelets, period doubling, and time-frequency localization with application to organization of convection over the tropical western Pacific. J. Atmos. Sci., 51, 2523-2541. 